\title{
Introduction
}

\section{Effective Loss Prevention Means Protecting Lives, Selling More and Losing Less}

\author{
Security Journal (2006) 19, 211-215. doi:10.1057/palgrave.sj.8350020
}

Individual retailers may make billions in revenue every year, but they also lose millions. These huge losses make security efforts vital to success, and even survival. For 30 or more years, retail security efforts have been called loss prevention (LP). LP rather than crime prevention is a fitting term since retail security executives are responsible for preventing both crime and non-crime (human and system errors, flaws and omissions) losses throughout the supply chain and stores. The challenge of preventing crime and loss means designing and deploying protective people, processes and systems (Hayes, 1997). Retail operations generally look for investments including those to prevent losses, providing financial or other demonstrable value to shareholders. This requirement means LP programmes be carefully developed and evaluated. However, traditional anecdotally based or weak R\&D designed programmes have not significantly changed retail loss levels over the last decade (Bamfield and Hollinger, 1996; Hollinger and Langton, 2005).

In order to effectively secure retail locations, their products and their employees and customers, protective research should be conducted to more accurately measure, explain and prevent shoplifting. Evidence-based research concepts are prevalent in medicine, education and politics, and stem from the belief that science distinguishes data from theory. These and other disciplines use systematic scientific testing for both recommendation and implementation in practice (Sherman, 2003). "An evidence-based approach requires that the results of rigorous evaluation be rationally integrated into decisions about interventions by policymakers and practitioners alike" (Petrosino, 2000a, b, 635).

Due to the criticality of "getting it right," evidence-based efforts have gained much support in medicine over the course of the decade. Historically, research within this field was based on theory, conjecture and untested new ideas. The U.S. Office of Technology Assessment estimated in 1983, 85 per cent of medical treatments had not been scientifically tested (as sited in Millenson, 1997, 4). With the implementation of evidence-based solutions, preventive efforts are based solely on solid evidence of what works (Sherman, 2003). The challenge for the asset protection discipline is to continue to formulate, produce, make available and make use of this new knowledge by practitioners and policy makers.

This recent movement of related disciplines has provided support for evidence-based research in crime prevention (Welsh and Farrington, 2001; Sherman, 2003). Although the term evidence-based action may be new to the field, the approach has been used for a number of years. Efforts within the social sector have been based on influencing policy, programming and practice through research. Demand for these methods has grown, "The collective voice for an evidence-based approach is becoming louder and more international in dialect. 
More researchers, practitioners and citizens seem to want to know what science says about policy or practice"'(Petrosino, 2000a, b, 635). In addition, demand for evaluation methods of these techniques has also increased. In 1997, The Report to Congress on Crime Prevention reviewed over 500 evaluation reports finding, "the effectiveness of most crime prevention strategies will remain unknown until the nation invests in evaluating them"(Sherman et al., 1997, 10-11). Skilled researchers using evidence-based methods means field practitioners will have better informed protective options, while the body of knowledge grows.

The spread of evidence-based methods continues from medicine to law enforcement to retail. Shapland (1995) discusses the problem in studying LP as obtaining a valid measurement of crime. "There is a dearth of empirical published research on problems of crime and the possibilities for crime prevention in the retail sector" (Shapland, 1995, 264). The research priorities are data on the extent and nature of crime problem, followed by studies to understand and determine which situational strategies are efficacious and financially effective. These efforts, similar to crime prevention, can ultimately be improved by moving to an evidence-based model. Since life safety, critical assets, and even corporate success and survival, are at stake, crime and LP initiatives should be focused, carefully designed and rigorously tested for real-world efficacy and cost-effectiveness. The move to evidence-based research will allow implementation of strategies that reflect leading scientific evidence on what works best at preventing crime (Welsh and Farrington, 2005). Improving protective efficacy with robust and replicated research remains a challenge for LP research.

\section{Previous research}

This Security Journal issue is designed to inform readers while promoting evidencebased loss prevention (EBLP). This issue is not the first use of EBLP, but rather is to build on the efforts of other scholars. In 1995, a review of crime prevention literature revealed, "crime prevention research has been dominated by two evaluative designs and a great deal of self-serving unpublished and semi-published work that does not meet even the most elementary criteria of evaluative probity" (Ekblom and Pease, 1995, 585-586). The report cited limitations of evaluation methods, shortcomings in implementing preventative action and poorly defined theory justifying action as inert problems with research studies. Research initiatives are often focused on efforts rather than results.

Recent publications address the importance of using systematic research to shape and evaluate crime and loss control methods, even providing a useful research rigour rating scale (Tilley, 1996; Crawford and Jones, 1996; Clarke, 1997; Sherman et al., 1997; Visher and Weisburd, 1998; Farrington and Petrosino, 2000; Farrington and Welsh, 2001; Painter and Farrington, 2001; Eck, 2002; Farrington and Painter, 2003; Sherman, 2003; Welsh and Farrington, 2006). These authors describe how randomized, controlled trials provide the most objective and measurable effectiveness data, with qualitative research providing insight into the observed quantitative data. However, due to the relatively new use of serious, systematic research in retail LP, rigour levels are not yet generally at those of other disciplines. Bearing this in mind, development and evaluation research in retail can take many forms including: using expert and staff interviews and surveys, offender interviews and 
process tracing, closed-circuit television (CCTV) video footage review, field observations, case studies, quantitative modelling, incident and merchandise handling process mapping, as well as simple before and after comparisons, and more sophisticated quasi-experimental designs.

With all of the research methodologies available within the retail sector, it is critical that techniques be evaluated. In Thinking About Crime Prevention (1997), Lawrence Sherman recommends confronting the body of research by using a scale to rate the strength of research studies. Sherman proposes three elements for consideration in research: reliable and statistically powerful measures and correlations (including adequate sample sizes and response rates), temporal ordering of the hypothesized cause and effect - so that programme 'cause' comes before the crime prevention 'effect' and valid comparison groups of other methods to eliminate other explanations, such as 'the crime rate would have dropped anyway' (Sherman, 1997, 46-51). Sherman's scale of evidentiary strength for cause and effect employs a 'methodological rigor' that rates seven different dimensions. It then evaluates the study on scientific strength and substantive findings to classify programmes into what works, what doesn't, what's promising and what's unknown. This is an attempt to understand, evaluate and cultivate the body of knowledge within crime prevention.

\section{This issue}

This special issue is dedicated to highlighting a handful of examples of research-informed LP using different methods to address critical topics. The authors provided papers explaining recent research completed in support of retail crime and loss control in order to simultaneously reveal research findings while demonstrating a variety of research methods.

Mike Scicchitano and Tracy John's paper starts off this issue by investigating research efforts of LP executives in retail companies to understand the source of retail loss and the effectiveness of employed techniques. The findings highlight the need for additional empirical research to enhance understanding of threats, as well as to guide, evaluate and refine asset protection efforts.

British researcher Paul Chapman provided a paper on measuring inventory shrinkage. Incredibly, even in this time, we are not able to consistently and accurately measure inventory losses in our stores and total retail operations. This not only makes it more difficult for retailers, but also harms our efforts to measure the results of protective efforts. Chapman ultimately recommends a two-part measurement system to gather pertinent information, but recognizes the challenge of effectively using the data to reduce shrinkage.

Angela Spriggs and Martin Gill provided a paper regarding the effectiveness of CCTV by discussing 14 case studies of public usage. Many retailers across the globe use CCTV in their stores, distribution centres and parking lots in order to deter, detect and record deviant behaviour. As is the case with most protective efforts, evidence-based CCTV best methods and efficacy is not well documented. This paper shows readers how qualitative approaches such as case study reviews, qualitative approaches and process evaluations can provide good insight into why a protective effort does or does not work, as well as recommend strategies for successful implementation. 
Adam Silverman's paper provides a unique perspective in that the author applies retail LP strategy to anti-terrorism, while providing terrorism control strategy and tactics perspective to retailing (of course malls and stores have been terrorism targets due to what they represent, and the large amount of humanity involved). Silverman builds on conventional retail theft reduction strategies to conceptualize using six security concepts as counter-terrorism and anti-terrorism strategy to secure commercial, retail, government and military facilities.

Finally, as promoted in the above works on evidence-based crime prevention, Read Hayes and Robert Blackwood's paper describes experimental research on the efficacy of electronic article surveillance in a large-store retail environment. The paper demonstrates the difficulty of conducting rigorous research in operating stores and emphasizes how vital statistical power is, since both sampling and measurement error are particularly abundant in the chaos of busy retail locations. The study also provides insight into using multi-method research in retail LP such as point of sale computer data, field observers, CCTV video review and quantitative hand counting to not only look for stable cause and effect relationships, but in order to better understand a study's final results.

Each of these papers was selected given that they shed further light on the need for, as well as the difficulties of real-world LP empirical research. The papers in this edition also illustrate the variety of research methods available to businesses and academics. Survey, case study and experimental designs are employed by these researchers. All methods have their strengths and weaknesses. Experimental designs provide stronger internal validity while sacrificing some generalization. Experiments also don't provide a lot of why an observed condition occurred, or what to do about it (this is why the authors in this issue simultaneously used video footage, interviews and field observers to help fill in the blanks). Likewise, case studies and surveys can lack some of the internal validity of other methods, but do provide more external validity. All of the included studies provide unique insight into retail problems and solutions. The point of this issue is to illustrate to ourselves and our industry the need for, the utility of, and the methods of using evidence-based asset protection.

I would like to thank these authors for their special efforts, as well as the peer reviewers and editors. All of these people are extremely busy, and their research, writing, editing and reviewing these important contributions to the body of knowledge are very much appreciated. I would also like to extend special thanks to assistant editors Bob DiLonardo, Candy Carmel-Gilfilen and Caroline Cardone for their perspectives and hard work on this special edition.

I sincerely hope this Security Journal issue provides some new and usable information to your practices, your research, your organizations, and your success.

Read Hayes

\section{References}

Bamfield, J. and Hollinger, R.C. (1996) Managing Losses in the Retail Store: A Comparison of Loss Prevention Activity in the United States and Great Britain. Security Journal. Vol. 7, No. 1, pp. 61-70.

Clarke, R.V. (1997) Introduction. In Clarke, R.V. (ed.) Situational Crime Prevention: Successful Case Studies, (2nd ed.) New York: Harrow and Heston: Guilderland. 
Crawford, A. and Jones, M. (1996) Kirkholt Revisited: Some Reflections on the Transferability of Crime Prevention Initiatives. The Howard Journal. Vol. 35, pp. 21-39.

Eck, J.E. (2002) Preventing Crime at Places. In Sherman, L.W., Farrington, D.P., Welsh, B.C. and MacKenzie, D.L. (eds) Evidence-Based Crime Prevention. London: Routledge, pp. 241-294.

Ekblom, P. and Pease, K. (1995) Evaluating Crime Prevention. In Toney, M. and Farrington, D.P. (eds) Building a Safer Society: Strategic Approaches to Crime and Justice. Crime and Justice: A Review of Research. Vol. 19, Chicago: University of Chicago Press.

Farrington, D.P. and Painter, K.A. (2003) How to Evaluate the Impact of CCTV on Crime. Crime Prevention and Community Safety: An International Journal. Vol. 5, No. 3, pp. 7-16.

Farrington, D.P. and Petrosino, A. (2000) Systematic Reviews of Criminological Interventions: The Campbell Collaboration Crime and Justice Group. International Annals of Criminology. Vol. 38, pp. 49-66.

Farrington, D.P. and Welsh, B.C. (2001) What Works In Preventing Crime: Systematic Reviews of Experimental and Quasi-Experimental Research. Thousand Oaks, CA: Sage.

Hayes, R. (1997) Retail Crime Control: A New Operational Strategy. Security Journal. Vol. 8, pp. $225-232$.

Hollinger, R. and Langton, L. (2005) 2004 National Retail Security Survey. Gainsville, Fl, USA: University of Florida.

Millenson, M. (1997) Demanding Medical Excellence: Doctors and Accountability in the Information Age. Chicago: University of Chicago Press.

Painter, K.A. and Farrington, D.P. (2001) Evaluating Situational Crime Prevention Using a Young People's Survey. British Journal of Criminology. Vol. 41, pp. 266-284.

Petrosino, A. (2000a) What Works to Reduce Offending? A Systematic Review of 300 Randomized Field Trials, Manuscript.

Petrosino, A. (2000b) How Can We Respond Effectively to Juvenile Crime? Pediatrics. Vol. 105, pp. $635-637$.

Shapland, J. (1995) Preventing Retail-Sector Crimes. In Tonry, M. and Farrington, D. (eds) Building a Safer Society: Strategic Approaches to Crime Prevention-Crime and Justice: A Review of Research. Vol. 19, Chicago: University of Chicago Press.

Sherman, L.W. (1997) Thinking About Crime Prevention. In Sherman, L.W., Gottfredson, D., MacKenzie, D., Eck, J., Reuter, P. and Bushway, S. (eds) Preventing Crime: What Works, What Doesn't, What's Promising. Washington DC: United States Department of Justice, Office of Justice Programmes, National Institute of Justice.

Sherman, L.W., Gottfredson, D., MacKenzie, D., Eck, J., Reuter, P. and Bushway, S. (1997) Preventing Crime: What Works, What Doesn't, What's Promising. Washington DC: United States Department of Justice, Office of Justice Programmes, National Institute of Justice.

Sherman, L. (2003) Misleading Evidence and Evidence-Led Policy: Making Social Science More Experimental. Annals of the American Academy of Political and Social Science. Vol. 589, pp. 6-19.

Tilley, N. (1996) Demonstration, Exemplification, Duplication and Replication in Evaluation Research. Evaluation. Vol. 2, pp. 35-50.

Visher, C.A. and Weisburd, D. (1998) Identifying What Works: Recent Trends in Crime Prevention Strategies. Crime, Law and Social Change. Vol. 28, pp. 223-242.

Welsh, B.C. and Farrington, D.P. (2001) Costs and Benefits of Preventing Crime. Boulder: Westview Press.

Welsh, B.C. and Farrington, D.P. (2005) Evidence-Based Crime Prevention: Conclusions and Directions for a Safer Society. Canadian Journal of Criminology and Criminal Justice. Vol. 47, No. 2, pp. 337-354.

Welsh, B.C. and Farrington, D.P. (2006) Closed-circuit television surveillance. In Welsh, B.C. and Farrington, D.P. (eds) Preventing Crime: What Works for Children, Offenders, Victims, and Places. Dordrecht: Springer, pp. 193-208. 